\title{
Results from Operational Testing of the Eaton Smart Grid Capable Electric Vehicle Supply Equipment
}

Brion Bennett

October 2014

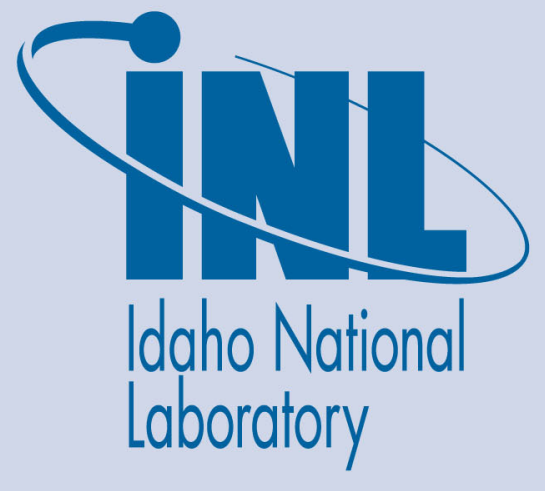

The INL is a U.S. Department of Energy National Laboratory operated by Battelle Energy Alliance 
INL/EXT-14-33401

Revision 1

\title{
Results from Operational Testing of the Eaton Smart Grid Capable Electric Vehicle Supply Equipment
}

\author{
Brion Bennett
}

October 2014

Idaho National Laboratory Idaho Falls, Idaho 83415

http://avt.inel.gov

Prepared for the

U.S. Department of Energy

Office of Electricity Delivery and Energy Reliability

Under DOE Idaho Operations Office

Contract DE-AC07-05ID14517 


\section{DISCLAIMER}

This information was prepared as an account of work sponsored by an agency of the U.S. Government. Neither the U.S. Government nor any agency thereof, nor any of their employees, makes any warranty, expressed or implied, or assumes any legal liability or responsibility for the accuracy, completeness, or usefulness, of any information, apparatus, product, or process disclosed, or represents that its use would not infringe privately owned rights. References herein to any specific commercial product, process, or service by trade name, trade mark, manufacturer, or otherwise, does not necessarily constitute or imply its endorsement, recommendation, or favoring by the U.S. Government or any agency thereof. The views and opinions of authors expressed herein do not necessarily state or reflect those of the U.S. Government or any agency thereof. 


\section{CONTENTS}

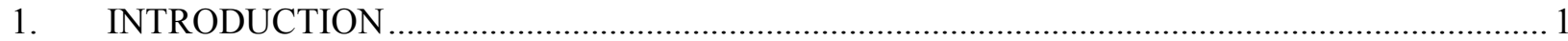

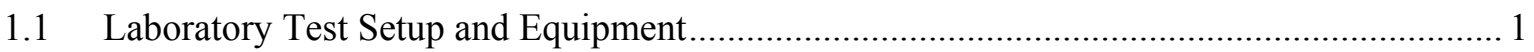

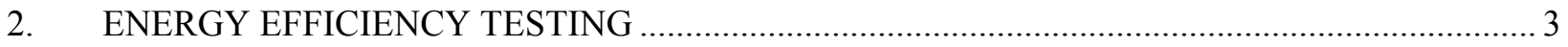

2.1 Electric Vehicle Supply Equipment Standby Power Consumption ..................................... 3

2.2 Electric Vehicle Supply Equipment Efficiency ................................................................. 3

2.3 Electric Vehicle Supply Equipment Energy Measurement ................................................. 4

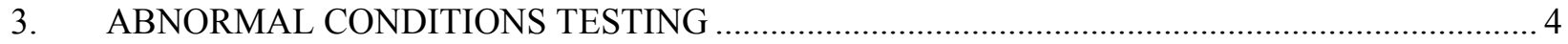

3.1 Electric Vehicle Supply Equipment Response to Abnormal Control Pilot Voltage ............... 4

3.2 Electric Vehicle Supply Equipment Response to Abnormal Input Voltage Condition........... 5

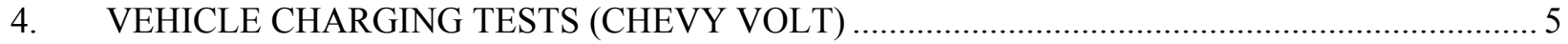

4.1 Electric Vehicle Supply Equipment Energy Efficiency ...................................................... 7

4.2 Electric Vehicle Supply Equipment Energy Measurement ................................................. 8

4.3 Electric Vehicle Supply Equipment Response to Interrupted Grid Power ........................... 8

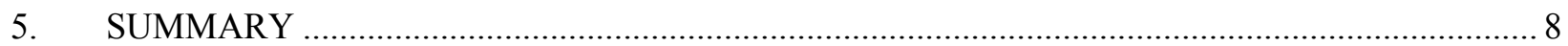

\section{FIGURES}

Figure 1. Eaton EVSE and the EVSE front panel display during operation......................................... 1

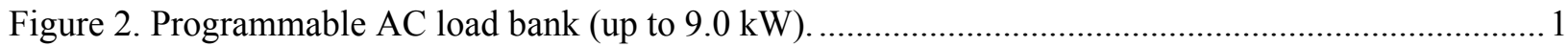

Figure 3. Hioki 3390 power meter and Eaton IQ 250 watt hour meter with GE CTM-0C current

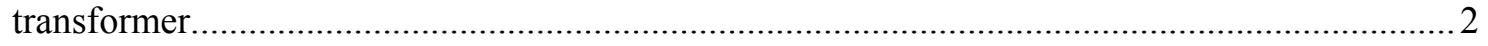

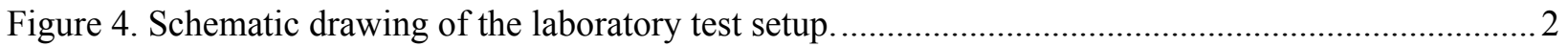

Figure 5. SAE J1772 (version 2010)-recommended practice of control pilot voltage range for

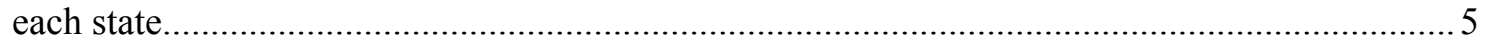

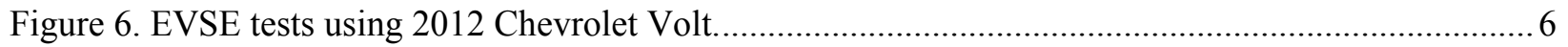

Figure 7. Mobile breakout box showing plugs, receptacles, current loops, and voltage taps..................... 6

Figure 8. Schematic drawing of the vehicle test setup...................................................................... 7

\section{TABLES}

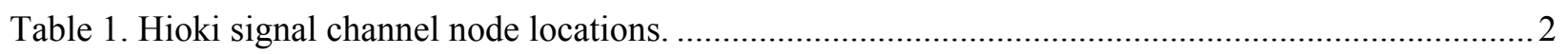

Table 2. Definition of vehicle states from SAE J-1772 standard.......................................................... 3

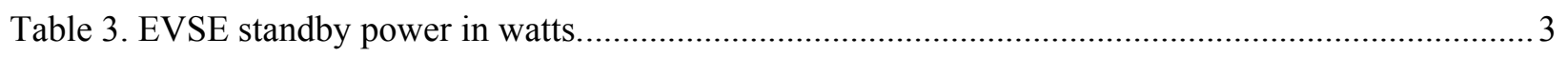

Table 4. Left plug (Plug \#1) EVSE efficiency testing. .................................................................... 4 
Table 5. Right plug (Plug \#2) EVSE efficiency testing. ..................................................................... 4

Table 6. EVSE response to abnormal control pilot voltage. .................................................................... 5

Table 7. Left plug (Plug 1) energy efficiency testing: EVSE efficiency over charge event....................... 7

Table 8. Right plug (Plug 2) energy efficiency testing: EVSE efficiency over charge event..................... 7 


\section{Results from Operational Testing of the Eaton Smart Grid Capable Electric Vehicle Supply Equipment \\ 1. INTRODUCTION}

The Idaho National Laboratory (INL) conducted testing and analysis of the Eaton smart grid capable electric vehicle supply equipment (EVSE), which was a deliverable from Eaton for the U.S. Department of Energy FOA-554. INL has extensive knowledge and experience in testing advanced conductive and wireless charging systems though INL's support of the U.S. Department of Energy's Advanced Vehicle Testing Activity. This document details the findings from EVSE operational testing conducted at INL on the Eaton smart grid capable EVSE (Figure 1). Testing conducted on the EVSE included energy efficiency testing, abnormal conditions testing, and charging of a production-level plug-in electric vehicle. SAE J1772 functionality testing was not performed due to the Grid Test EVE-100L Lab Test Unit being inoperable and unable to initialize.
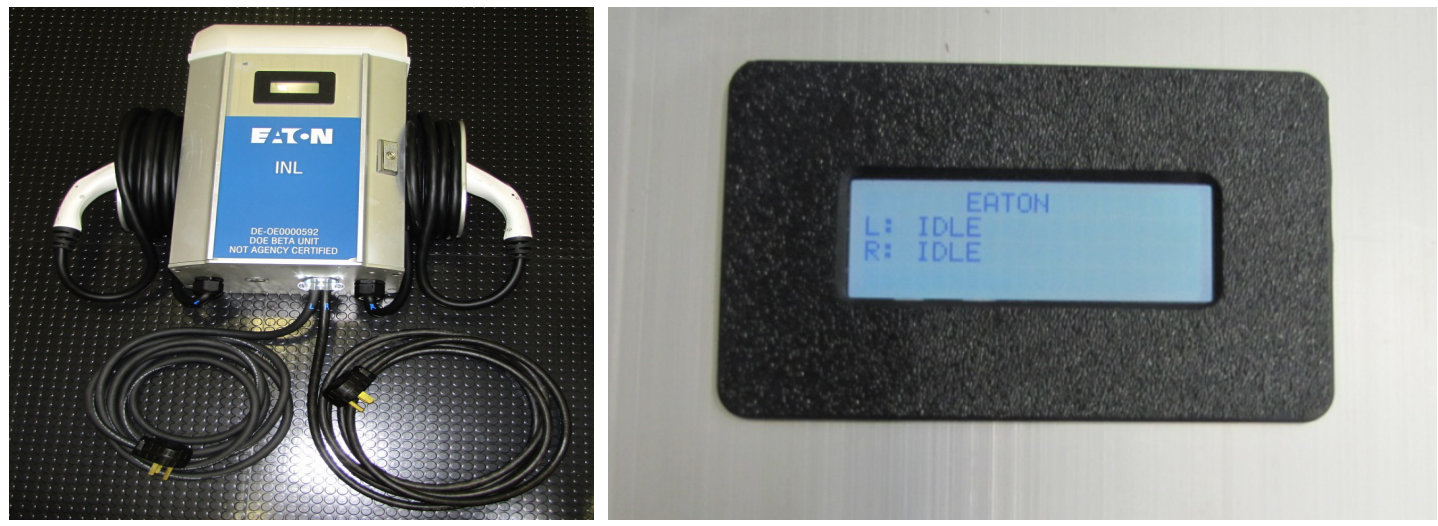

Figure 1. Eaton EVSE and the EVSE front panel display during operation.

\subsection{Laboratory Test Setup and Equipment}

For laboratory testing of the EVSE, vehicle emulation equipment was utilized, including a control pilot emulation module and a programmable alternating current (AC) load bank. The control pilot emulation module contained multiple resistors and a National Instruments' relay module that was controlled to provide proper resistance to the control pilot during testing to request the desired operation state. To draw power from the EVSE, a programmable AC load bank, which is capable of up to $9.0 \mathrm{~kW}$, was utilized (Figure 2).

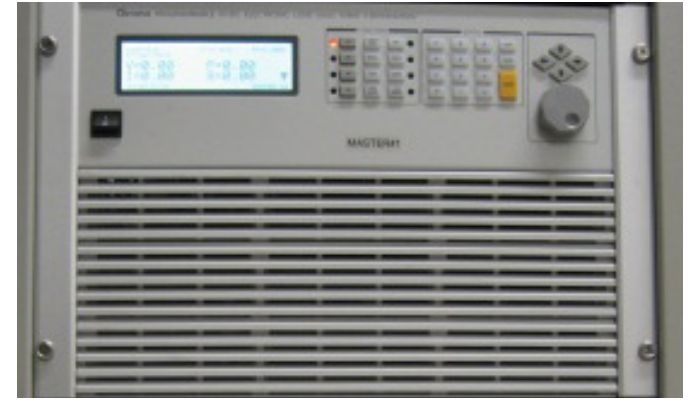

Figure 2. Programmable AC load bank (up to $9.0 \mathrm{~kW}$ ).

Two pieces of calibrated measurement equipment (Figure 3) were used to measure voltage, current, and energy at multiple nodes during testing. A Hioki 3390 power meter was used to measure the input 
node and output node and control the pilot signal of the EVSE. An Eaton IQ 250-watt hour meter, with a GE CTM-0C current transformer, also was used to measure the output node of the EVSE.
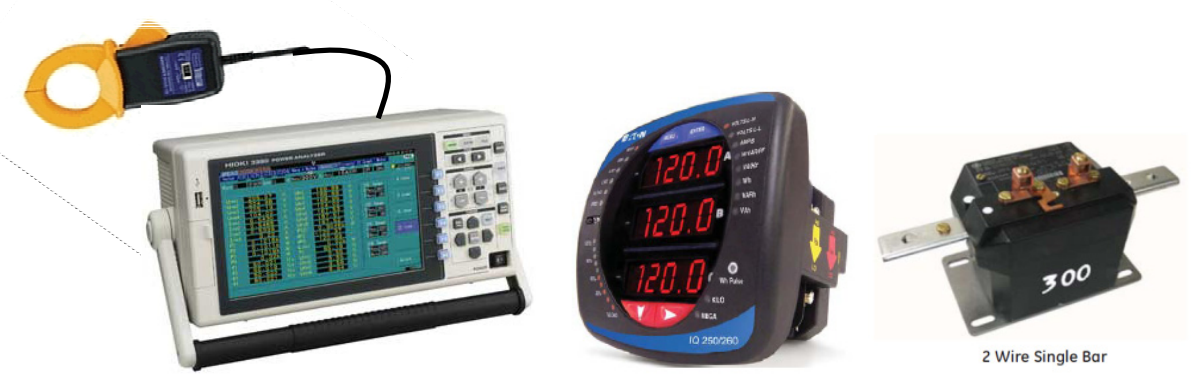

Figure 3. Hioki 3390 power meter and Eaton IQ 250 watt hour meter with GE CTM-0C current transformer.

A schematic of the test setup is shown in Figure 4. The input voltage of 208 VAC was supplied from a single 40-A circuit breaker to a safety stop (i.e., E-stop) module that contained two contactors (one per line) and a status light. The voltage output from the E-stop module was connected to both EVSE input connectors. The chosen EVSE output (Plug 1 or Plug 2) was connected to an enclosure that housed the Eaton IQ250 watt hour meter. The control pilot emulation module was connected next in the series to provide the appropriate resistance for the desired J1772 state. Finally, the power was absorbed by the AC programmable load. The Hioki voltage taps and current clamps were located as shown in Figure 4 and detailed in Table 1.

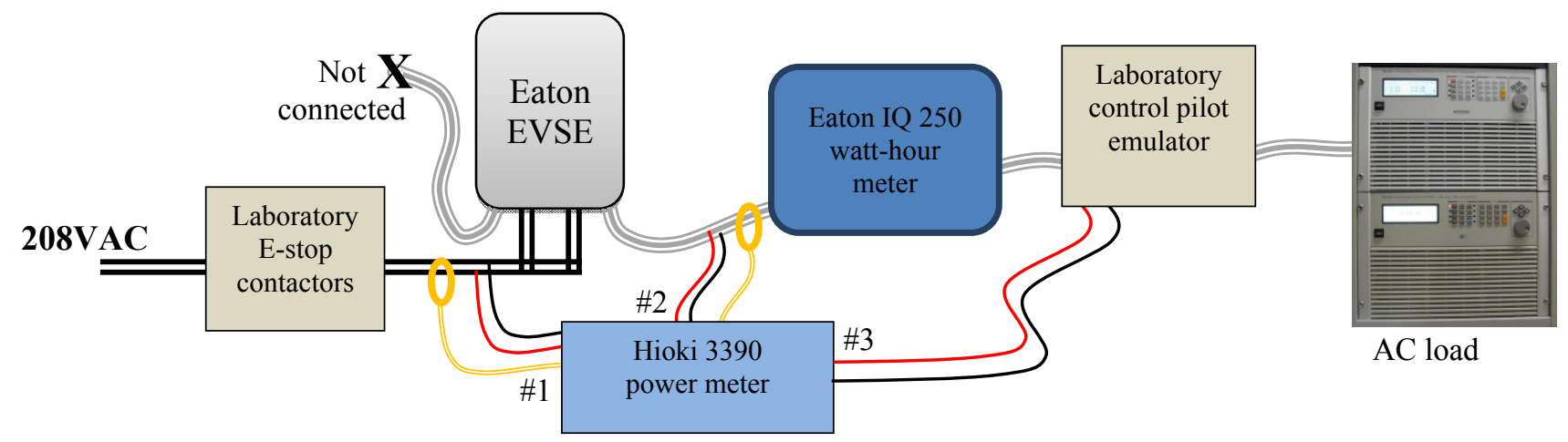

Figure 4. Schematic drawing of the laboratory test setup.

Table 1. Hioki signal channel node locations.

\begin{tabular}{lll}
\hline Hioki Channel & \multicolumn{1}{c}{ Voltage Node } & \multicolumn{1}{c}{ Current Node } \\
\hline Channel 1 & Combined input to EVSE & Combined input to EVSE \\
Channel 2 & Output from selected J1772 connector & Output from selected J1772 connector \\
Channel 3 & Control pilot signal & Open \\
Channel 4 & Open & Open \\
\hline
\end{tabular}




\section{ENERGY EFFICIENCY TESTING}

EVSE testing was conducted in the laboratory for both the left and right J1772 plug (i.e., Plug 1 and Plug 2). Energy testing was done at four EVSE output power levels (i.e., $0.05 \mathrm{~kW}, 1.1 \mathrm{~kW}, 3.3 \mathrm{~kW}$, and $6.2 \mathrm{~kW}$ ), where each power level was tested for 10 minutes. EVSE standby power consumption also was tested to determine the amount of energy the EVSE uses while in a passive, non-charging state. Various power levels were chosen because they represent typical charge rates for a wide range of plug-in vehicles such as Level 1 and Level 2. The highest output power tested was limited to $6.2 \mathrm{~kW}$, because of the 32 -amp input continuous current limit of the 40 -amp circuit breaker with a $20 \%$ safety factor. The nominal input voltage was 208 VAC. Details from the energy efficiency testing are described in the following subsections.

\subsection{Electric Vehicle Supply Equipment Standby Power Consumption}

EVSE standby power consumption was tested for the following J1772 states: State B, State C, and State D. Table 2 provides a summary of the state descriptions in the SAE J1772 standard. In State B, the EVSE was connected to a vehicle, but the vehicle was not ready to charge; therefore, the contactor in the EVSE was open. In State C and State D, the EVSE was connected to a vehicle and the vehicle had communicated to the EVSE that it was ready to charge; therefore, the contactor in the EVSE was closed if all conditions are correct. The results from these tests are summarized in Table 2. As seen in Table 3, the behavior of the two plugs is almost identical for the various J1772 states. In addition, the standby power of State $\mathrm{C}$ is about 3 watts greater than the standby power of State B. This is likely due to the power required to keep the contactors closed in State C. Finally, no standby power was recorded for State D because the contactor did not close due to a fault. The EVSE display shows "Fault," with a LED indicator visibly red and a power reset was performed to clear the error.

Table 2. Definition of vehicle states from SAE J-1772 standard

\begin{tabular}{lcc}
\hline J1772 State & $\begin{array}{c}\text { Voltage } \\
(\text { Vdc })\end{array}$ & State Description \\
\hline State A & 12.0 & Vehicle not connected \\
State B & 9.0 & Vehicle connected/not ready to accept energy \\
State C & 6.0 & Vehicle connected/ready to accept energy/indoor ventilation not required \\
State D & 3.0 & Vehicle connected/ready to accept energy/indoor ventilation required \\
State E & 0.0 & EVSE disconnected/Power unavailable/or other problem \\
State F & -12.0 & EVSE not available/or other problem \\
\hline
\end{tabular}

Table 3. EVSE standby power in watts.

\begin{tabular}{lcc}
\hline J1712 State & Left Plug (Plug \#1) & Right Plug (Plug \#2) \\
\hline State B & 11.9 Watts & 11.8 Watts \\
State C & 15.1 Watts & 15.1 Watts \\
State D & NA & NA \\
\hline
\end{tabular}

\subsection{Electric Vehicle Supply Equipment Efficiency}

The EVSE efficiency, as measured by the Hioki 3390 power meter, for Plug \#1 and Plug \#2 can be found in Tables 3 and 4. Of the four power levels measured, the efficiency is the best when $3.3 \mathrm{~kW}$ is being drawn from the EVSE. The efficiency at very low power levels (i.e., 50 watts) is lower because the EVSE standby power is large compared to the output power drawn from the EVSE. The efficiency also 
drops slightly at high power levels (i.e., $6.2 \mathrm{~kW}$ ) due to the resistive losses caused by the large currents at high power levels. Comparing the results from the two plugs, the results are almost identical at the measured power levels for Level 1 and Level 2 charging.

Table 4. Left plug (Plug \#1) EVSE efficiency testing.

Average EVSE Efficiency

Test Condition

(Output Power/Input Power)

50 watts

$77.0 \%$

$1.1 \mathrm{~kW}$

$98.3 \%$

$3.3 \mathrm{~kW}$

$98.7 \%$

$6.2 \mathrm{~kW}$

$98.1 \%$

Table 5. Right plug (Plug \#2) EVSE efficiency testing.

Average EVSE Efficiency

Test Condition

(Output Power/Input Power)

50 watts

$76.9 \%$

$1.1 \mathrm{~kW}$

$98.3 \%$

$3.3 \mathrm{~kW}$

$98.5 \%$

$6.2 \mathrm{~kW}$

$97.8 \%$

It has been noted that during testing activities that required the control pilot to transition from State $\mathrm{C}$ to State B, the EVSE repeatedly displayed an error on the front panel display (error 32). The Eaton engineering staff is aware of the condition and is working to resolve it.

\subsection{Electric Vehicle Supply Equipment Energy Measurement}

Energy measurement tests using the Hioki 3390 power meter, the IQ 250 watt hour meter, and the EVSE front panel displays were not performed. The Eaton EVSE front panel display did not provide a cumulative watt hour reading for energy usage validation. However, it did provide a reading of the charge current that refreshed at a relatively slow rate (i.e., only a few times per minute), but this was insufficient for cumulative energy comparison purposes. Because of the absence of an EVSE-provided energy measurement, the laboratory evaluation of the EVSE energy meter was not performed.

\section{ABNORMAL CONDITIONS TESTING}

In addition to the previously described testing at normal conditions, testing was also conducted to determine the response of EVSE to abnormal input conditions.

\subsection{Electric Vehicle Supply Equipment Response to Abnormal Control Pilot Voltage}

Previously, each of the control pilot states was tested (State A, B, C, and D). Additionally, testing was conducted at control pilot voltages that are outside of the voltages specified by SAE J1772 for each control pilot state. Figure 5 shows the SAE J1772-recommended practices for the EVSE manufacturer for state determination from the control pilot voltage. 


\begin{tabular}{lcccc}
\hline & Minimum & Nominal & Maximum \\
\hline Positive Voltage, State A & 11.40 & 12.00 & 12.60 \\
Positive Voltage, State B & 8.36 & 9.00 & $\ddots$ & 9.56 \\
Positive Voltage, State C & 5.48 & 6.00 & $\ddots$ & 6.49 \\
Positive Voltage, State D & 2.62 & 3.00 & $\cdots$ & 3.25 \\
Negative Voltage - States B, C, D, and F & -11.40 & -12.00 & $\cdots$ & -12.60 \\
\hline
\end{tabular}

Figure 5. SAE J1772 (version 2010)-recommended practice of control pilot voltage range for each state.

Two control pilot voltage conditions were tested: Control Pilot $=7.3 \mathrm{~V}$ (between State B and C) and Control Pilot $=4.8 \mathrm{~V}$ (between State C and D). For both Plug 1 and Plug 2, the contactors closed at the tested control pilot voltage as shown in Table 7.

Table 6. EVSE response to abnormal control pilot voltage.

\begin{tabular}{cccc}
\hline Test Condition & CP Voltage Peak+ & $\begin{array}{c}\text { Between States } \\
\text { (per J1772) }\end{array}$ & Eaton EVSE Response \\
\hline Plug 1 ("Left") & $7.3 \mathrm{~V}$ & B and C & Contactors closed \\
Plug 1 ("Left") & $4.8 \mathrm{~V}$ & C and D & Contactors closed \\
Plug 2 ("Right") & $7.3 \mathrm{~V}$ & B and C & Contactors closed \\
Plug 2 ("Right") & $4.9 \mathrm{~V}$ & C and D & Contactors closed \\
\hline
\end{tabular}

\subsection{Electric Vehicle Supply Equipment Response to Abnormal Input Voltage Condition}

Testing was conducted to identify EVSE functionality when only a single input to the EVSE is supplied with $208 \mathrm{VAC}$ as compared to when both inputs are powered from $208 \mathrm{VAC}$.

When the right input power was connected to 208 VAC and either Plug \#1 (left charge cord) or Plug \#2 (right charge cord) were connected, the LCD displays did not light (completely dark) and the EVSE had no functionality. The control pilot was static (no pulse width modulation) in all control pilot states. Also, the contactors did not close when State $\mathrm{C}$ was requested; therefore, the EVSE did not supply voltage to the vehicle for charging.

Conversely, when the left input power was connected to 208 VAC and either Plug \#1 (left charge cord) or Plug \#2 (right charge cord) was connected, the LCD display was lit with normal indications and the EVSE contactors closed, which supplied voltage to the vehicle for charging. In State $\mathrm{C}$, the control pilot pulse width modulation duty cycle was about $50 \%$. The vehicle was able to successfully charge. Additionally, the EVSE plugs' status of both plugs (monitored via the Eaton "user software" application) were observed to be "charging" when charging and "idle" when not connected.

\section{VEHICLE CHARGING TESTS (CHEVY VOLT)}

Vehicle charging tests were performed with a 2012 Chevrolet Volt (Figure 6), which is an extended range electric vehicle, to observe EVSE operations during real-world charging events. Under these conditions, the efficiency and standby loads of the EVSE were observed and measured. Secondary observations that were made included charge ramp up and ramp down as dictated by the vehicles onboard charger.

The Volt was driven before each test to fully deplete the battery pack until charge-sustaining mode was reached. A full charge event was then initiated, monitored, and recorded using the Hioki 3390 power analyzer and Eaton IQ 250 watt hour meter. 
A mobile, in-line breakout box (Figure 7) was constructed to enable the safe and easy connection of current and voltage measurements without the need to modify the EVSE or the vehicle. The breakout box contained two independent sections that each contained conductor loops and voltage taps to which the Hioki current clamps and voltage taps were connected. The two sections were housed within one enclosure for ease of transport. The first section was a pass-through of grid power to the EVSE. The second section was the EVSE J1772 output, which was passed through to another J1772 connector that was plugged into the vehicle $\mathrm{J} 1772$ charge port.

Figure 8 shows the connection schematic for the breakout box, Hioki 3390 power meter, and the Eaton IQ 250 watt hour meter used for vehicle testing. Measurement at the input of the EVSE is node \#1 and measurement at the SAE J1772 output connector of the EVSE is node \#2 (Figure 8).

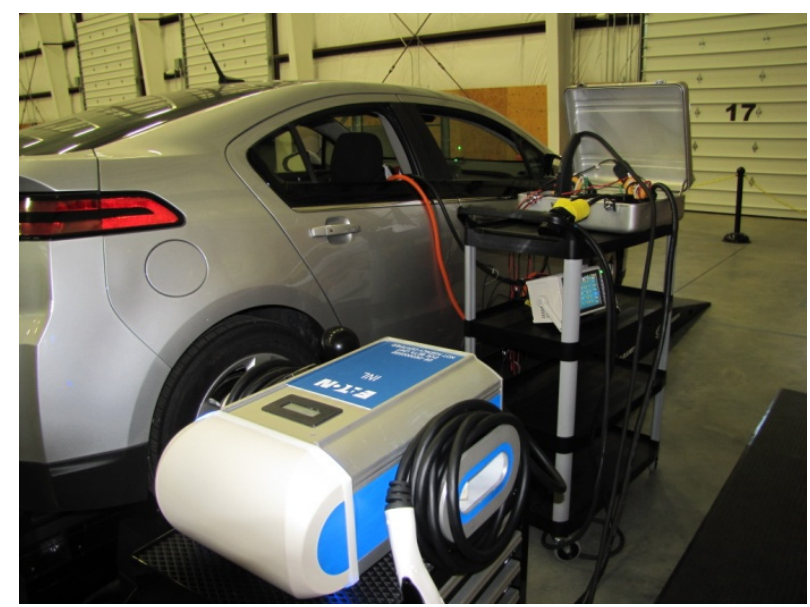

Figure 6. EVSE tests using 2012 Chevrolet Volt.
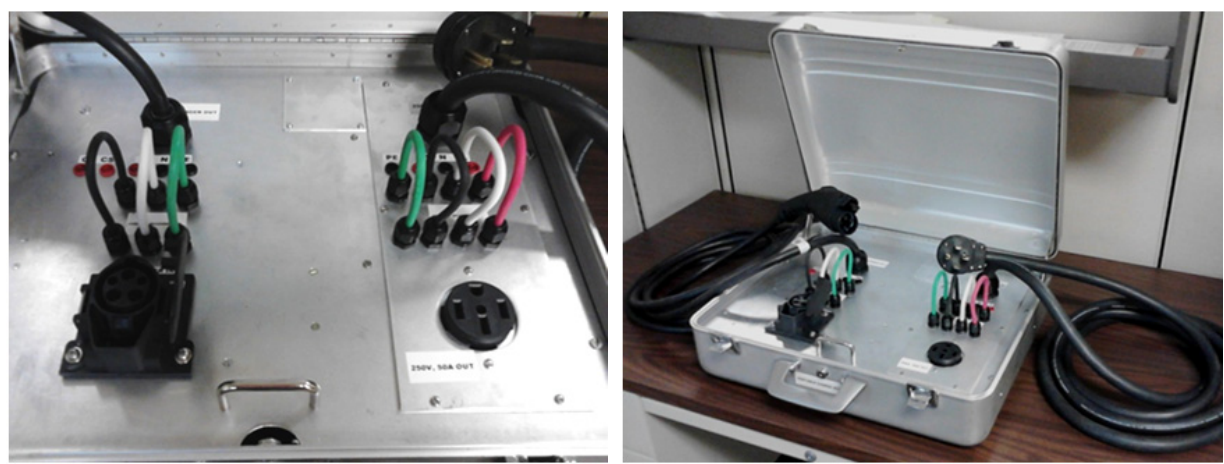

Figure 7. Mobile breakout box showing plugs, receptacles, current loops, and voltage taps. 


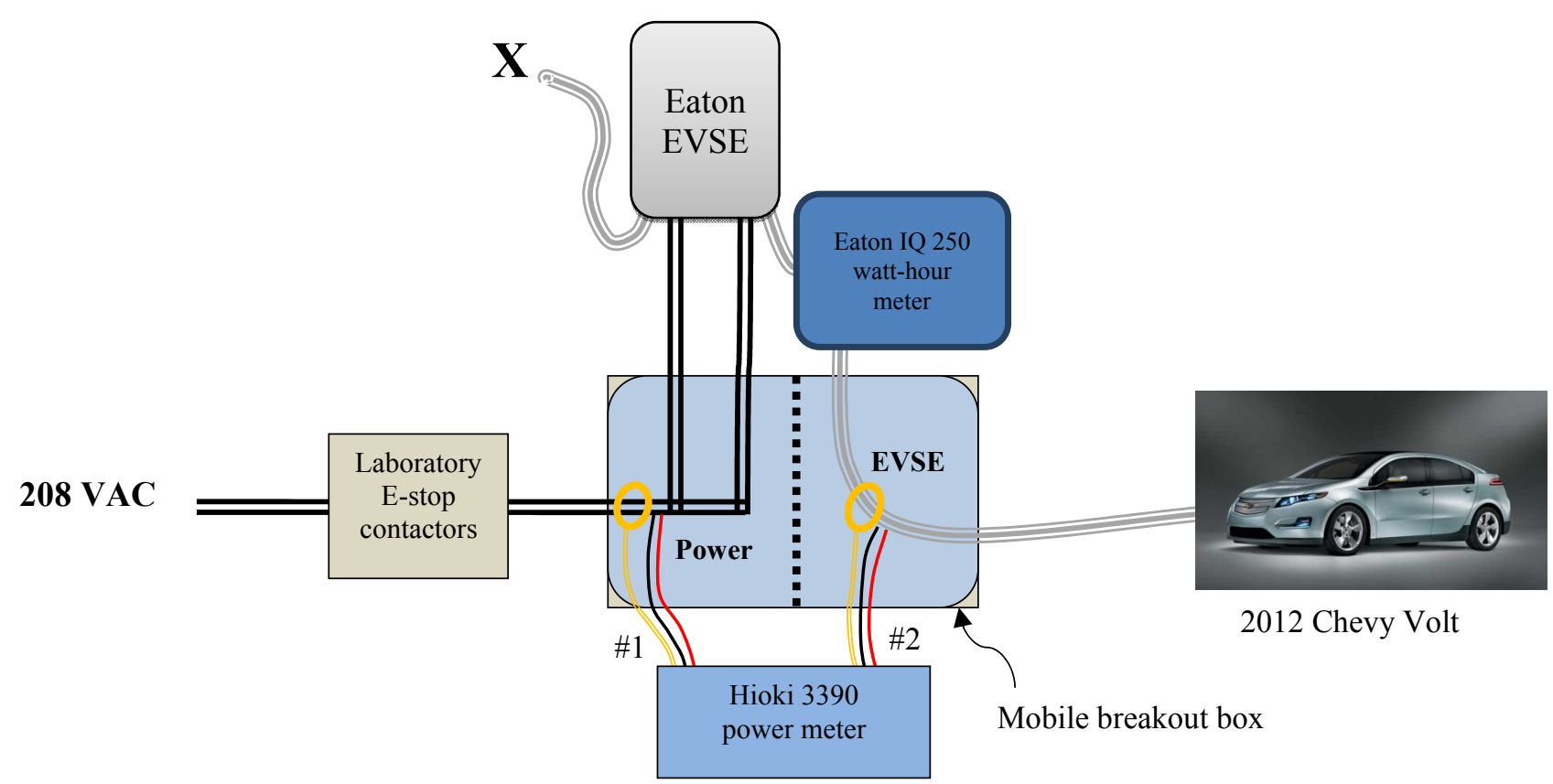

Figure 8. Schematic drawing of the vehicle test setup.

\subsection{Electric Vehicle Supply Equipment Energy Efficiency}

The EVSE energy transfer was measured throughout a full charge event for the Chevy Volt. This charge event was approximately 4.5 hours in duration and nominal power transfer was $3.1 \mathrm{~kW}$ as controlled by the vehicle's battery management system. From the cumulative measured energy delivered to the vehicle and the cumulative energy supplied to the EVSE from the grid, the efficiency of the EVSE can be determined over the entire charge event. Tables 6 and 7 show the energy efficiency of the EVSE for Plug \#1 and Plug \#2. Energy efficiency is defined as the total energy output from the EVSE divided by the total energy input to the EVSE over the entire duration of the charge event. The EVSE efficiency was measured to be $98.0 \%$ for the left plug and $97.8 \%$ for the right plug. This is nearly the same as the 98.5\% result shown in Table 4 that was measured during laboratory testing at the slightly higher 3.3-kW power level.

Table 7. Left plug (Plug 1) energy efficiency testing: EVSE efficiency over charge event.

EVSE Efficiency

Test Condition

(Total Output Energy/Total Input Energy)

Vehicle Full Charge Event

$98.0 \%$

Table 8. Right plug (Plug 2) energy efficiency testing: EVSE efficiency over charge event.

EVSE efficiency

Test Condition (Total Output Energy/Total Input Energy)

Vehicle Full Charge Event

$97.8 \%$

It has been noted that during testing activities that required the control pilot to transition from State $\mathrm{C}$ to State B, the EVSE repeatedly displayed an error on the front panel display (error 32). The Eaton engineering staff is aware of the condition and is working to resolve it. 


\subsection{Electric Vehicle Supply Equipment Energy Measurement}

As previously seen in laboratory testing, energy measurement tests using the Hioki 3390 power meter, the IQ 250 watt hour meter, and the EVSE front panel displays were not performed. The Eaton EVSE front panel display did not provide a cumulative watt hour reading for energy usage validation. However, it did provide a reading of the charge current that refreshed at a relatively slow rate (only a few times per minute), but this was insufficient for cumulative energy comparison purposes. Because of the absence of an EVSE-provided energy measurement, the laboratory evaluation of the EVSE energy meter was not performed.

\subsection{Electric Vehicle Supply Equipment Response to Interrupted Grid Power}

Testing was conducted on the EVSE to identify the EVSE response to a grid power outage. This test was conducted using the Chevy Volt vehicle testing protocols described above. A vehicle charging event was initiated and nominal charge power was reached and monitored for approximately 1 minute to ensure proper steady-state operation. Grid power (208 VAC) was then interrupted simultaneously for both EVSE power inputs. The EVSE ceased to function or provide voltage to the vehicle as expected. Grid power was restored after approximately 5 seconds and the EVSE rebooted. After approximately 60 seconds, the EVSE reinitiated the charge event without the need for outside intervention. The charge event continued as expected.

\section{SUMMARY}

INL tested the Eaton smart grid capable EVSE in support of the U.S. Department of Energy FOA554. Energy efficiency, stand-by power consumption, and functionality per SAE J1772 were tested. The EVSE also was used to charge a 2012 Chevy Volt to verify full functionality with a production plug-in electric vehicle.

The test results of the Eaton EVSE showed the nominal operating efficiency for both Plug \#1 and Plug \#2 is greater than $98 \%$ during Level 2 charging. The standby power consumption was measured to be 11.9 watts in State B (vehicle connected, but not ready to charge) and 15.1 watts in State C (vehicle connected and ready to charge). The EVSE front panel display shows the current in amps instead of a cumulative energy (such as watt-hours). Therefore, validation tests of EVSE energy measurements were not performed. It has been noted that during testing activities that required the control pilot to transition from State C to State B, the EVSE repeatedly displayed an error on the front panel display (error 32). The Eaton engineering staff is aware of the condition and is working to resolve it. The Eaton smart grid capable EVSE successfully charged a production plug-in electric vehicle from both Plug \#1 and Plug \#2 during functional tests. 